\title{
The effect of virgin nylon addition into recycled nylon on the fatigue strength of thermoplastic nylon denture base
}

\author{
Siti Wahyuni ${ }^{1 *}$, Jeewena Ravichanthiran ${ }^{1}$ \\ 'Department of Prosthodontics, Faculty of Dentistry University of North Sumatra, Indonesia
}

\begin{abstract}
Introduction: Thermoplastic nylon denture base is processed through injection molding process. This manipulation technique produces non-biodegradable nylon wastes which have to be recycled. Recycling of nylon wastes is feasible due to the linear molecular structure of thermoplastic nylon. This study aimed to know the effect of adding virgin nylon into recycled nylon on the fatigue strength of thermoplastic nylon denture base. Methods: This research was experimental laboratory research using 27 samples of thermoplastic nylon with three different groups (100\% virgin nylon, $100 \%$ recycled nylon and combination of $60 \%$ of virgin nylon with $40 \%$ of recycled nylon) using injection molding technique. The test results were analyzed using one-way ANOVA test to know the differences in the mean value of the fatigue strength of each group and LSD test to know the effect of adding $60 \%$ of virgin nylon into $40 \%$ of recycled nylon. Resuts: Results showed significant results $(p<0,05)$, as well as LSD test that showed there is effect of adding $60 \%$ of virgin nylon into $40 \%$ of recycled nylon on the fatigue strength of thermoplastic nylon denture base. Conclusion: The combination of $60 \%$ of virgin nylon with $40 \%$ of recycled nylon showed higher fatigue strength than the recycled nylon.
\end{abstract}

Keywords: Thermoplastic nylon, denture base, nylon wastes, recycling process, fatigue strength.

p-ISSN: 1979-0201; e-ISSN: 2549-6212; Available from: http://jurnal.unpad.ac.id/pjd/article/view/23903

DOI: 10.24198/pid.vol32no1.23903

Submission: Jul 13, 2019; Accepted: Mar 25, 2020; Published online: Mar 31, 2020

\section{INTRODUCTION}

Thermoplastic nylon is used for the fabrication of flexible dentures. ${ }^{1}$ This material generally replaces the metal and the methyl methacrylate denture base material which is used conventionally to build standard removable partial dentures framework. It is nearly unbreakable, esthetically acceptable and can be fabricated quite thin. It is stable in nature, provides resistance to polymer unzipping, high creep resistance and fatigue endurance. Flexible dentures exhibit viscoelastic behavior that lead to improvement in masticatory function and patients comfort compared with hard dentures. ${ }^{2}$

However, thermoplastic nylon has certain disadvantages such as high water absorption, tendency of the base color to deteriorate and also difficult to adjust and polish. ${ }^{3}$ One of the 
mechanical properties of thermoplastic nylon which is of concern in its use as a denture base material is fatigue strength.

Fatigue strength is the stress level at which a material fails under repeated loading. ${ }^{4}$ Many materials which are used as dental prostheses are subjected to intermittent stresses over a long period of time. Although the stresses encountered may be far to small to cause fracture of a material, over a period of time, failure may occur by a fatigue process. ${ }^{5}$ Nylon has higher fatigue strength and resistance to repeated stressing because nylon is a crystalline polymer which has more or less ordered parallel packing of the long-chain molecules which is caused by strong attractive forces between the chains. The consequence is more a perfect parallel orientation of the molecules in the direction of elongation, which result in considerable increase in mechanical properties. ${ }^{3,6}$

The injection moulding process of thermoplastic nylon denture base produces nylon wastes in the sprue that will be discarded after the process. The accumulation of non-biodegradable nylon wastes causes serious ecological problem due to the inability of nylons to decompose within a reasonable time frame. ${ }^{7}$ Therefore, mechanical recycling is a good option for reducing environmental problems caused by polymeric waste accumulation.

However, nylons are easily subjected to thermal, oxidative and mechanical degradation during processing. Degradation phenomenon not only results in brittleness and deterioration of the mechanical properties of nylons, but also decreases the stability and restricts the application of the final products. So, as to overcome the decreased fatigue strength of recycled nylon, modification technique must be carried out by adding virgin nylon into recycled nylon. ${ }^{8}$ Therefore, this study was aimed to analyse the effect of virgin nylon addition into recycled nylon on the fatigue strength of thermoplastic nylon denture base.

\section{METHODS}

This research was experimental laboratory research using thermoplastic nylon as specimens with three different groups (100\% virgin nylon, $100 \%$ recycled nylon, and combination of $60 \%$ of virgin nylon with $40 \%$ of recycled nylon). A total of 27 specimens $(65 \mathrm{~mm} \times 10 \mathrm{~mm} \times 3 \mathrm{~mm}$ ) based on International Standard Organization (ISO 1567 Standard) were fabricated, divided into nine samples for each group. ${ }^{9}$

The nylon wastes processing stage were divided into several stages such as, cutting, contaminant separation, washing and drying. Thermoplastic nylon from each group was injected into the mould prepared in the injection flask and obtained three samples per injection. The specimens were then smoothed by using the waterproof sandpaper that fixed in the rotary grinder and polished by using Scotch-Brite brush with coarse pumice.

Tensile test of the specimen from each group was carried out to obtain the ultimate stress of the specimen by using Universal Testing Machine. Then, the fatigue test was performed in a Servohydraulic Tester: MTS Bionix 858 by applying $50 \%$ of the ultimate stress obtained repeatedly through tension compression loading until fracture occurs. The frequency used was 10 $\mathrm{Hz}$. The number of loading cycles to failure of the specimens were reported. The test results were analysed using one-way ANOVA test and Least Significant Different (LSD) test.

\section{RESULTS}

Table 1. The mean fatigue strength values and standard deviations for three groups tested

\begin{tabular}{cccc}
\hline \multirow{2}{*}{ Specimen number } & \multicolumn{2}{c}{ Fatigue strength (Number of loading cycles to failure) } \\
\cline { 2 - 4 } & $\begin{array}{c}\text { Group A (60\% of virgin nylon } \\
\text { with 40\% of recycled nylon) }\end{array}$ & $\begin{array}{c}\text { Group B (100\% recycled } \\
\text { nylon) }\end{array}$ & Group C (Nylon combination) \\
\hline $1 \times 10^{5 *}$ & $16.20 \times 10^{5}$ & $10.47 \times 10^{5}$ & 14.86 \\
$2 \times 10^{5}$ & $18.25 \times 10^{5 *}$ & $11.09 \times 10^{5}$ & 13.66 \\
$3 \times 10^{5}$ & $18.10 \times 10^{5}$ & $10.30 \times 10^{5}$ & 13.80 \\
$4 \times 10^{5}$ & $16.58 \times 10^{5}$ & $10.16 \times 10^{5}$ & 12.92 \\
$5 \times 10^{5}$ & $17.93 \times 10^{5}$ & $9.77 \times 10^{* *}$ & 11.48
\end{tabular}




\begin{tabular}{|c|c|c|c|}
\hline $6 \times 10^{5}$ & $15.29 \times 10^{5}$ & $9.83 \times 10^{5}$ & 12.18 \\
\hline $7 \times 10^{5}$ & $16.31 \times 10^{5}$ & $10.96 \times 10^{5}$ & 11.11 \\
\hline $8 \times 10^{5}$ & $15.93 \times 10^{5}$ & $9.92 \times 10^{5}$ & 13.02 \\
\hline $9 \times 10^{5}$ & $17.23 \times 10^{5}$ & $9.82 \times 10^{5}$ & 13.95 \\
\hline $\bar{X} \pm S D \times 10^{5} \pm$ & $16.87 \times 10^{5} \pm$ & $10.25 \times 10^{5} \pm$ & 12.99 \\
\hline$\times 10^{5}$ & $1.06 \times 10^{5}$ & $4.95 \times 10^{4}$ & 1.23 \\
\hline
\end{tabular}

Table 2. One-way ANOVA test in comparisons of the mean fatigue strength values for three groups tested

\begin{tabular}{cccc}
\hline Group & \multicolumn{4}{c}{ Fatigue strength (Number of loading cycles to failure) } \\
\cline { 2 - 4 } & $\mathrm{n}$ & $\overline{\mathrm{X}}_{ \pm} \mathrm{SD}$ & $\mathrm{P}$ \\
\hline $\begin{array}{c}\mathrm{A} \\
\pm 1.06 \times 10^{5}\end{array}$ & 9 & $16.87 \times 10^{5}$ & \\
$\mathrm{~B}$ & & $10.25 \times 10^{5}$ & $0.001^{*}$ \\
$\pm 4.95 \times 10^{4}$ & 9 & $12.99 \times 10^{5}$ & \\
$\mathrm{C}$ & & & \\
$\pm 1.23 \times 10^{5}$ & 9 &
\end{tabular}

Table 3. LSD test on the effect of adding $60 \%$ of virgin nylon into recycled nylon on the fatigue strength of thermoplastic nylon denture base

\begin{tabular}{cccc}
\hline Group & Group A & Group B & Group C \\
\hline Group A & & $\mathrm{p}=0.0001^{*}$ & $\mathrm{p}=0.0001^{*}$ \\
Group B & $\mathrm{p}=0.0001^{*}$ & & $\mathrm{p}=0.0001^{*}$ \\
Group C & $\mathrm{p}=0.0001^{*}$ & $\mathrm{p}=0.0001^{*}$ & \\
\hline
\end{tabular}

Key: *Significant

\section{DISCUSSION}

Table 1 presents the number of loading cycles required to cause failure of each specimen from each group tested. The mean fatigue strength value and standard deviations for three group tested have been also shown in Table 1. The 50\% of ultimate stress of group A (100\% virgin nylon) was $18.05 \mathrm{MPa}$, group B (100\% recycled nylon) was $15.2 \mathrm{MPa}$ and group C (combination of $60 \%$ of virgin nylon with $40 \%$ of recycled nylon) was 17.95 MPa obtained.

The results of this study show that the specimens from each group have widely varying fatigue strength values due to the factors affecting the fatigue strength during processing of the denture materials. Pero et al. ${ }^{10}$ reported that the higher the porosity of a material, the lower the mechanical properties of the material. Microporosity is formed during the injection molding process and hence lower the fatigue strength when more micro-porosity is formed because air enters during processing and cause the materials to be easily fractured when subjected to loading. ${ }^{10}$
In addition, the higher the degree of crystallinity of nylon, the higher the fatigue strength due to the dense intermolecular space of nylon. ${ }^{11}$ The polishing technique also causes a considerable reduction in the fatigue strength because the rotary grinder formed lines on the surface of the specimens which act as stress concentration. ${ }^{12}$

Table 2 shows significant results $(p<0.05)$ of differences in the mean value of the fatigue strength of each group. The mean value of the fatigue strength shows that group $C$ has higher fatigue strength than group $B$. However, group $A$ has the highest value of the fatigue strength. Kuram et al..$^{13}$ compared the mechanical properties of virgin nylon with recycled nylon and the results showed that virgin nylon has better mechanical properties than recycled nylon. The fatigue strength of the specimens depends on the amount of the percentage of recycled nylon. The higher the percentage of recycled nylon, the smaller the number of loading cycles to failure. Maspoch et al. ${ }^{12}$ reported that the percentage of recycled nylon should be less than the percentage of virgin nylon and the best combination is $70 \%$ of virgin 
nylon with $30 \%$ of recycled nylon. However, in this study to optimize the usage of nylon wastes, the percentage of recycled nylon is increased to $40 \%$.

The virgin nylon consists of peptide units $(\mathrm{NH}-\mathrm{CO})$ that form hydrogen bonding between the polymer chain. This hydrogen bond gives strong attractive forces between the molecule chain with ordered arrangement and dense intermolecular space of molecules. ${ }^{6}$ However, in recycled nylon the $\mathrm{C}-\mathrm{C}$ bonds of the polymer chain were broken and resulted in formation of shorter polymer chain. The bond between polymer chain become weaker, less orderly, intermolecular space become less dense and hence crystallinity decreases. Similarly, Solya et al. ${ }^{7}$ reported the mechanism of chain scission occurred due to the mechanical recycling of nylon. The results in Fourier Transformed Infrared Spectroscopy (FTIR) showed that the methyl $(\mathrm{CH} 3)$ increases whereas the methylene $(\mathrm{CH} 2)$ decreases. Therefore, the deterioration in the fatigue strength was the consequence of polymer degradation. ${ }^{9}$

Table 3 shows that there was a significant difference between each group with $p=0,0001$ $(p<0,05)$. Therefore, there was an effect of adding $60 \%$ of virgin nylon into recycled nylon on the fatigue strength of thermoplastic nylon denture base. Vinay et al. ${ }^{14}$ stated that there is effect of adding virgin nylon into recycled nylon because of the formation of crystalline amide which occur between components in virgin nylon and recycled nylon. The nylon structure of group $C$ is more superior compared to group $B$ because the hydrogen bond from the virgin nylon added fill into the amorphous region of the recycled nylon and so chain extension reaction takes place. The intermolecular space become denser, crystallinity increases and hence fatigue strength increases. ${ }^{15}$

\section{CONCLUSION}

The combination of $60 \%$ of virgin nylon with $40 \%$ of recycled nylon have higher fatigue strength than the recycled nylon. Therefore, the material have superior properties and characteristics and provide good esthetic and biocompatible treatment options to help patients with missing teeth.

\section{REFERENCES}

1. Sharma A, Shashidhara HS. A review: Flexible removable partial dentures. Int Org Sci Res J Dent Med Sci. 2014;13(12):58-62. DOI: 10.9790/0853-131265862

2. Vikhe DM, Saraf V, Gangadhar SA, Bhandari A, Vikhe G, Tambe SD. Flexible denture-a flexible substitute for rigid denture. Pravara Med Rev. 2016;8(1):30-32.

3. Kohli S, Bhatia S. Polyamides in dentistry. Int $J$ Sci Stud. 2013;1(1):20-25.

4. Sakaguchi RL, Powers JM. Craig's Restorative Dental Materials. $13^{\text {th }}$ ed. St. Louis: MosbyElsevier; 2013. p. 83-88.

5. McCabe JF, Walls AWG. Applied Dental Materials. $9^{\text {th }}$ ed. Oxford: Blackwell Publishing; 2008. pp. 13-40,119-32.

6. Kohli S, Bhatia S. Flexural properties of polyamide versus injection-molded polymethylmethacrylate denture base materials. Eur J Prosthod. 2013;1(3):56-60. DOI: $10.4103 / 2347-4610.119792$

7. Sólya J, Miskolczi N. Degradation of reinforced and unreinforced waste polyamides during mechanical recycling. Hung J Indust Chem Veszprém. 2013;41(2):131-6.

8. Hamad K, Kaseem M, Deri F. Recycling of waste from polymer materials. Polym Degrad Stabil. 2013;98(12):2801-12. DOI: 10.1016/j. polymdegradstab.2013.09.025

9. Gurbuz O, Dikbas I, Unalan F. Fatigue resistance of acrylic resin denture base material reinforced with E-glass fibres. Gerodontology. 2012;29(2):710-4. DOI: $10.1111 / j .1741-$ 2358.2011.00548.x

10. Pero AC, Marra J, Paleari AG, de Souza RF, Ruvolo-Filho A, Compagnoni MA. Reliability of a method for evaluating porosity in denture base resins. Gerodontology. 2011;28(2):12733. DOI: $10.1111 / j .1741-2358.2009 .00347 . x$

11. Ali AA. Strain life failure of HDPE, PP and PMMA polymers. Al-Taqani. 2013;26(5):144-153.

12. Maspoch ML, Ferrando HE, Velasco Jl. Characterisation of filled and recycled PA6. Macromol Symp. 2003;194(1):295-304. DOI: $10.1002 /$ masy.200390096

13. Kuram E, Tasci E, Altan Al, Medar MM, Yilmaz 
F, Ozcelik B. Investigating the effects of recycling number and injection parameters on the mechanical properties of glass-fibre reinforced nylon 6 using Taguchi method. Mater Design. 2013;49:139-50. DOI: 10.1016/j. matdes.2013.02.027

14. Vinay MN, Ravishankar S, Girish TP, Radhakrishnan R, Ananthapadmanabha GS, Shashidhara GM. Effect of addition of reprocessed nylon 6 with virgin material for roller assembly used in printers. J Appl Polym Sci. 2000;78(10):1737-43.

15. Bucella M, Dorigato A, Pasqualini E, Caldara M, Fambri L. Thermo-mechanical properties of Polyamide 6 chemically modified by chain extension with Polyamide/Polycarbonate blend. J Polym Res. 2012;19:9935. DOI: 10.1007/s10965-012-9935-0 